\title{
Rethinking legal objectives for climate-adaptive conservation
}

\author{
$\underline{\text { Jan McDonald }}^{1,2}, \underline{\text { Phillipa C. McCormack }}^{1}, \underline{\text { Aysha J. Fleming }}^{2,3}, \underline{\text { Rebecca M. B. Harris }}^{4}$ and Michael Lockwood $^{5}$
}

\begin{abstract}
This paper examines conservation objectives in Australian law in the context of climate change. The rate of climate change and the scale and extent of its impacts on natural systems drive the need to re-evaluate current conservation objectives, from basic concept definitions, to overarching goals and values, to the way they are operationalized at all levels. We outline the case for reform of objectives in the legal framework for conservation and discuss three key strategies that would facilitate this transition: (1) acknowledgment in conservation law of system dynamism; (2) focus on ecosystem function, stability, and resilience; and (3) an explicit recognition that systems operate across multiple scales. Law reform is a slow process, but the potential of climate change to drive transformational changes means that urgent action is needed to overcome the limitations of current objectives and in the legal framework itself.
\end{abstract}

Key Words: Climate change adaptation; conservation law; conservation objectives; law reform

\section{INTRODUCTION}

This article contributes to emerging understandings of the role of law in promoting climate change adaptation (Craig 2010, McDonald 2011) by focusing specifically on how conservation objectives are articulated in nature conservation, protected area, and threatened species laws and policies. The conservation of biodiversity under climate change is the subject of extensive scholarly inquiry across the disciplines of conservation biology (e.g., Hoegh-Guldberg and Bruno 2010, Bellard et al. 2012), environmental planning (e.g., Gillson et al. 2013, Rickards et al. 2014), and public policy (e.g., Chaffin et al. 2014, Koontz et al. 2015). Conservation practitioners and researchers have identified several key strategies for promoting climate-adaptive conservation practices, including enhancing protected areas and connectivity, reducing or removing existing stressors, and in some cases, relocation and ex situ conservation measures (Seabrook et al. 2011, Hagerman and Satterfield 2014). These studies have not necessarily questioned the overarching societal goals of conservation practice under climate change, and the limited literature that has done so (e.g., Heller and Hobbs 2014, Harris et al. 2015) has not considered how such goals should be operationalized through our laws and policies.

Conservation objectives in law perform a range of functions and are crucial to how action for biodiversity conservation is developed, funded, implemented, and assessed (McCormack and McDonald 2014). They clarify the broad aspirational outcomes sought by decision makers in crafting and implementing conservation policies and strategies and guide agency priorities and resource allocation. Provided they are drafted with sufficient specificity, legal objectives set a reference point to test the effectiveness of conservation activities. In cases of ambiguity or uncertainty, they also inform judicial interpretation of substantive legal obligations for conservation.

We examine how conservation objectives are articulated in the legal regime for nature conservation in Australia's island state of Tasmania in the context of the conservation challenges facing that jurisdiction. Tasmania is a good case study as it requires consideration of objectives derived from international, national, and state-level laws. In articulating the case for reform, we identify problems with the existing approach and interpret the findings for contemporary conservation law practice more generally. We consider the ways in which current objectives tend to promote conservation management approaches that may be unachievable under future climate change. In proposing a path for operationalizing reform options, the barriers to and drivers of future reform are considered, as well as the potential cobenefits of pursuing a new approach. We conclude that altering our conservation aspirations is a critical first step in making our legal regime more climate adaptive, but that deeper reform of legal instruments, tools, and agency mandates will also be needed to ensure that those objectives are embedded in conservation management practice.

\section{STRUCTURE AND METHODS}

This paper is a result of an extensive literature review, preparation of a discussion paper, a workshop, and the project team's regular discussions over a 12-month period. As such, it is an exploratory paper outlining perceived limitations in the legal specification of conservation objectives and opportunities to address these, rather than an empirical study. We limit our scope to those objectives directed toward conserving terrestrial biodiversity in Tasmania.

To explore whether there was support for reform of objectives in Tasmania, we invited conservation practitioners to a workshop to discuss the issues raised in a discussion paper outlining current research on law reform under climate change. Our aims for the workshop were: to draw out how current conservation objectives in law influenced the choice of strategies and actions; to find out whether there was general support for reform, and what form it might take; and to identify what processes, barriers, tools, and other issues would be important to consider. Nine local practitioners involved in conservation and related areas of interest (planning, government, environment, public advocacy groups) attended the workshop: four from government planning and environmental departments, two from advocacy groups, and one each from local government, academia, and an environmental law nongovernment organization.

${ }^{1}$ Faculty of Law, University of Tasmania, ${ }^{2}$ Centre for Marine Socioecology, ${ }^{3}$ CSIRO Land and Water, ${ }^{4}$ Antarctic Climate and Ecosystems Cooperative Research Centre, University of Tasmania, ${ }^{5}$ Geography and Spatial Sciences, School of Land and Food, University of Tasmania 
The workshop was small to allow time for in-depth discussion and interaction among participants. The project team facilitated specific activities designed to stimulate discussion in both roundtable format and breakout groups, but otherwise limited their speaking to allow the focus to remain on participants' perspectives. The workshop was audio recorded, and pertinent quotations transcribed. Participants also completed a worksheet of barriers and enablers, and these were collated. The transcripts and worksheets, together with findings from the literature, workshop, and authors' experiences, provide evidence in support of the ideas and conclusions presented in the sections of this paper titled "The Case for Reform," "A Systems Approach to Conservation Objectives in Law," and "Pathways to Reform."

In the next section, we present a review of the key legislation and plans associated with Tasmanian biodiversity objectives. We then identify key issues based on our review of the literature and doctrinal analysis (Hutchinson and Duncan 2012). We explore potential options for reform and suggest pathways by which these reforms could be progressed. We present integrated findings from the literature, workshop, and authors' experiences.

\section{LEGAL APPROACHES TO TASMANIAN CONSERVATION OBJECTIVES}

Conservation objectives may be explicit or implicit. Explicit conservation objectives include clauses in legislation or statutory management plans and legislative directions to decision makers. For example, the objectives of Australia's national environmental law, the Environment Protection and Biodiversity Conservation Act 1999 (Cth) (EPBC Act) include to "provide for the protection of the environment" and to "promote the conservation of biodiversity"(s3(1)). To achieve its objectives, the EPBC Act states that it must:

... [enhance] Australia's capacity to ensure the
conservation of its biodiversity by including provisions
to:... (i) protect native species ( and in particular prevent
the extinction, and promote the recovery, of threatened
species) and ensure the conservation of migratory species.

Objectives can also be found in statutory directions to decision makers, for example where legislation requires that "the Minister must take into account" or "have regard to" a particular matter in making a decision. Some laws impose an obligation to pursue legislative objectives in public activities more generally. For example, the Threatened Species Protection Act 1995 (Tasmania) (TSPA) states that:

\section{It is the obligation of any person on whom a function is imposed, or a power is conferred, under this Act to perform the function or to exercise the power in such a manner as to further the objectives specified in Schedule 1 [s4, emphasis added].}

Implicit objectives can be discerned by considering how a law seeks to achieve its explicit objects - the legal tools and instruments used. In Australia, the primary legal mechanisms for achieving explicit objectives focus on protected areas and listed threatened species. As will be shown below, this structuring of legal mechanisms implies that Australian conservation law prioritizes rare native species and considers wilderness places as being of higher conservation value than other elements of biodiversity, including diverse genes and ecosystems. The biophysical context for conservation of Tasmania's biodiversity and the interplay of explicit and implicit objectives are explored in the following subsections.

\section{Conservation challenges in Tasmania}

Tasmania is a cool, temperate island located $240 \mathrm{~km}$ to the south of the Australian mainland. It is separated by Bass Strait, which is approximately $350 \mathrm{~km}$ wide. As a result of the island's long geographic isolation and topographic diversity, there are a large variety of habitats and high numbers of endemic flora and fauna species. For example, $28 \%$ of known native vascular plant species are endemic. Tasmania has two World Heritage Areas with outstanding universal natural values, comprising $23 \%$ of the land area of the state: Tasmanian Wilderness and Macquarie Island. Overall, half of the state is managed for conservation within public $(48.7 \%)$ or private $(1.4 \%)$ reserves.

Tasmania has warmed at a rate of $0.1^{\circ} \mathrm{C}$ per decade since the $1950 \mathrm{~s}$, and average temperatures are projected to increase by 2.6 $3.3^{\circ} \mathrm{C}$ by the end of the century under a high emissions scenario. This rate is lower than that observed across mainland Australia $\left(0.16^{\circ} \mathrm{C}\right.$ per decade $)$ and the globe $\left(0.12{ }^{\circ} \mathrm{C}\right.$ per decade $)$ (Intergovernmental Panel on Climate Change (IPCC) 2014), because of Tasmania's maritime climate and southerly location.

As the climate changes and species on mainland Australia start to shift south to track cooler conditions, Tasmania is being heralded as a potential refuge for many species (e.g., Garnett and Zander 2014). However, for cool temperate and alpine species adapted to Tasmanian conditions, there are no options for range shifting because Tasmania is the southernmost land mass between the mainland and Antarctica.

The challenges facing conservation under climate change in Tasmania are illustrated by research into the changing climate suitability for the Ptunarra brown butterfly (Oreixenica ptunarra) and the Tasmanian lowland temperate native grasslands. The Ptunarra brown butterfly is listed as vulnerable under the Tasmanian TSPA. Tasmanian lowland temperate native grasslands are listed as a "Critically Endangered Ecological Community" under the EPBC Act. Less than $10 \%$ of the natural extent of this community remains, mostly on private freehold land. Remnant patches in good condition are species rich and important habitat to a diverse array of flora and fauna (Harris et al. 2015), many of which are also listed as vulnerable or threatened.

Recent research suggests that the climatic suitability for the listed lowland native grasslands may contract under climate change and that the rate of this change is rapid (Harris et al. 2015). As the climate becomes less suitable, a gradual change is expected in species composition, structure, and habitat quality of the grassland communities. Attempting to conserve the current composition of the grassland communities may not be possible, and new benchmarks will be needed to judge management success. In such cases, conservation biologists are increasingly recommending that management should focus on maintaining diversity, structure, and function, rather than attempting to preserve current species composition (Dunlop et al. 2013, Heller and Hobbs 2014).

There is considerable uncertainty associated with all projections of future change. Projections for the Ptunarra brown butterfly 
varied widely depending on how the models were parameterized. The species was projected either to experience very little contraction of habitat or to come close to extinction by the end of the century due to lack of suitable climate (Harris et al. 2013). Therefore, it is not possible to predict exactly what changes will occur in response to the changing climate or the location or timing of such change.

Current legal approaches to conservation are not designed to cope with such uncertainty or with changing boundaries or composition of community types. Legal mechanisms for protecting grasslands include formal reservations with fixed boundaries recorded on property titles and long-term conservation covenants over private land. Management success is judged through indicators such as the abundance of listed threatened species and floristic composition. Similarly, one of the specific objectives of the recovery plan for the Ptunarra brown butterfly is to "ensure the species persists long-term throughout its area of occupancy" (Bell 1998: 3), yet attempts to maintain a static baseline may no longer be viable under a changing climate.

\section{Conservation objectives in Tasmanian law}

The legal framework for conservation in Tasmania is a nested hierarchy of instruments from international, national, state, and local levels. International agreements, particularly the Convention on Biological Diversity (CBD) and the Convention Concerning the Protection of the World Cultural and Natural Heritage (World Heritage Convention), set high-level objectives. The CBD legitimizes the emphasis given to species conservation in national and state legislation. The World Heritage Convention supports national legislation that protects world heritage areas from development that would significantly affect world heritage values.

Consistent with the approach across Australian states, Tasmania's conservation laws and management arrangements take a twotiered approach. Primary emphasis is on reservation of large areas of public land primarily for conservation purposes. The second tier involves the listing and protection of threatened species, typically by requiring consideration or balancing of the impacts of specific development through environmental impact assessment frameworks. Conservation legislation also supports proactive management activities, such as the preparation and implementation of species recovery plans, but resource constraints greatly limit the effectiveness of such measures.

Protected area law is primarily a matter for the states, but with Tasmania having both world heritage areas and listed species under the EPBC Act, the Australian Government also has a role in securing the conservation of the state's biodiversity. Australia's Strategy for the National Reserve System 2009-2030 provides broad guidance for that management, recognizing that the primary means of securing long-term protection for Australia's terrestrial biodiversity is a "comprehensive, adequate and representative" national system of protected areas.

Tasmanian legislation for establishing protected areas sets out broad objectives. Schedule 1 of the Nature Conservation Act 2002 (Tasmania) (NCA) establishes the classes of protected area into which land may be reserved and lists the values and purposes of reservation for each class. Management objectives for each class are set out in Schedule 1 of the National Parks and Reserves
Management Act 2002 (Tasmania) (NPRMA). The relevant objectives for management of national parks, for example, are:

(a) to conserve natural biological diversity; ...

(d) to conserve sites or areas of cultural significance; ...

(g) to protect the national park against, and rehabilitate the national park following, adverse impacts such as those of fire, introduced species, diseases and soil erosion on the national park's natural and cultural values and on assets within and adjacent to the national park;

(h) to encourage and provide for tourism, recreational use and enjoyment consistent with the conservation of the national park's natural and cultural values; ...

(j) to preserve the natural, primitive, and remote character of wilderness areas.

Site-specific objectives may also be set in statutory management plans developed by reference to the objectives for that class of reservation. For example, the Tasman National Park and Reserves Management Plan specifies objectives under thematic headings such as:

- Flora: The objectives of vegetation conservation in the park and reserves are to: protect and maintain ongoing evolutionary processes; protect, maintain, and monitor natural flora diversity, threatened flora species, and communities of conservation significance; minimize harmful impacts on flora; and provide opportunities for the public to enjoy flora.

- Fauna: The objectives for fauna conservation in the park and reserves are to: protect, maintain, and monitor threatened fauna species; protect, maintain, and monitor the diversity of indigenous fauna and habitat; minimize harmful impacts on indigenous fauna and habitats; and provide opportunities for visitors to encounter wildlife.

The management plan then specifies "policies" and "actions" through which these objectives are to be achieved. However, the meanings of "protect" and "maintain" are undefined, and the difference between the two is unclear. "Maintain," for example, could mean ensuring all species currently present in the park continue to be extant into the future, and/or that their current populations are sustained, and/or that their distributions remain as at present.

The objectives of Tasmania's TSPA include:

- to ensure that all native flora and fauna in Tasmania can survive, flourish and retain their potential for evolutionary development in the wild; and

- to ensure that the genetic diversity of native flora and fauna is maintained (Sch 1; Part $2 \mathrm{cl}$ 3(a), (b), emphasis added).

"Survival" is defined as "the continued existence of viable populations of a taxon in the wild," so the objective is to enable all species to remain in "an independent, unpossessed or natural state" (TSPA s3). In practice, these objectives can only be operationalized through substantive protections under the Act for listed threatened species. Listing processes may not cover all 
taxa equally because of unconscious priorities, bias in the nomination process, or for political or practical reasons, including the availability of information and community awareness. Listed species may fall into one of a number of categories, including endangered, vulnerable, or rare. As a result, certain rare and popular or iconic species are more likely to be the subject of the TSPA's protection than other less well-known or identifiable species.

No legislation explicitly identifies whether the main purpose of species protection is to prevent extinction, avoid new species being added to statutory threatened species lists, or reduce the threats to already listed species. The Tasmanian legislation appears to seek all three, but does not prioritize or provide direction on how this might be achieved, other than to impose penalties for "taking" listed species, and to establish mechanisms for threat abatement and recovery plans (TSPA ss51, 25, 27).

A more forward-looking and adaptive conservation ambition is articulated in Tasmania's Natural Heritage Strategy, the aim of which is to:

\section{improve conservation outcomes in Tasmania by taking a coordinated, strategic landscape approach to conservation and management, including strategic planning and assessment. (Department of Primary Industries, Water and Environment (DPIPWE) 2013)}

The objectives articulated in Tasmanian protected area and threatened species laws are underpinned by the goals of a Resource Management and Planning System (RMPS), which are set out in annexes to key land-use planning and conservation statutes. The RMPS objectives include "to promote the sustainable development of natural and physical resources and the maintenance of ecological processes and genetic diversity." Statutory functions under protected area and threatened species legislation must be exercised "having regard to" or "to further" the RMPS objectives, but there is no guidance about the relative priority to be given to conservation over other listed social, economic, and cultural objectives.

\section{THE CASE FOR REFORM}

Three key themes emerge from the overview of Tasmanian conservation objectives set out in the previous section: (i) an emphasis on maintaining the current status and location of ecosystems and their constituent parts, or returning them to an "undisturbed" state; (ii) a high value placed on rarity, nativeness, and wildness; and (iii) focus on specific parcels of reserved land as the sites for most conservation effort. These themes have important implications for conservation law and policy, particularly given the expected influence of climate change on the state's biodiversity.

\section{Maintaining current status and location}

The likelihood of range shifts under climate change means that areas need to be identified and managed for both present and future habitat. In some cases, this means ensuring that areas can be made available for conservation in the future, whereas other areas may require active restoration. Enhancing connectivity between suitable areas is also recognized as a critical feature of climate adaptive approaches. Yet the emphasis of current objectives tends to view the conservation estate and associated systems as static. For example, the definition of "habitat" in the TSCA refers only to the habitat currently occupied by a listed taxon, which limits the impetus for restoration of degraded areas or active management of areas for future habitat. Similarly, reference to preserving the "natural state" of protected areas suggests a static or specific baseline. The TSPA's reference to maintaining the "evolutionary potential of species in the wild" acknowledges change processes, but arguably only at the pace and over timescales that have been experienced historically.

\section{Valuing rarity}

Current objectives place a high value on rarity, which is in turn a key criterion for the intensive application of conservation effort and resources in practice. Substantive legal protection and practical conservation effort are prioritized to direct limited conservation resources toward protecting those species closest to being lost to extinction. Threatened species regimes like the TSPA and EPBC Act place species into categories of threat, from "critically endangered" and "endangered" to "vulnerable" or "rare," each defined in relation to their proximity to extinction. The most threatened species are most likely to be listed, receive prioritized funding, and benefit from recovery planning and threat abatement efforts. As one workshop participant commented:

\section{The Environment Protection and Biodiversity Conservation Act and most of the state Acts have an overwhelming emphasis on species-level conservation and rarity, which to me, on reflection, seems quite bizarre, given all we know now.}

In the past, individual species have been valued as surrogates for more general concepts of biodiversity (Dunlop et al. 2013). Yet the most interactive species, including those that are common, may be far more important to ongoing ecosystem function and, in the face of rapid decline, their loss may be more likely to cause ecosystem transformation. It may be necessary to value biodiversity, and particularly rare species, in a different way so that their function becomes more important than their population size. Indeed, the strong emphasis on avoiding extinction in the wild may not only be increasingly hard to achieve, it may actually prove undesirable in terms of broader ecosystem health and resilience, especially if areas are managed to provide critical habitat for single species (Steffen et al. 2009, Camacho et al. 2010). This is not to suggest that we advocate giving up on the conservation of rare species or accept that the extinction of any species is acceptable. However, in some cases, the reality of climate change may force a reorientation of the current strong emphasis on protection in the wild.

\section{Valuing nativeness}

The Tasmanian conservation objectives outlined above place a high value on native and indigenous species over other species. There are 43 references to "native" species in the TSPA. Some definitions of native species are limited to a very particular subset of Australia's biodiversity (McCormack and McDonald 2014). Only species "naturally occurring in Tasmania" may be listed as threatened under the TSPA, and thus qualify for substantive protection (TSPA ss $25,27,32,51$ ). The EPBC Act has one of the broadest definitions of "native species," but still limits the term to a species that: 
is indigenous to Australia or an external Territory (or its seabed or coastal sea); members of which periodically or occasionally visit; or that was present in Australia or an external Territory before 1400 (s528, emphasis added).

State legislation is often more restrictive, defining native species as "indigenous" or as "continuous residents," including "periodic visitors," but does not define those additional terms. Although there is certainly a role for legal objectives that emphasize the conservation of native species, the implicit priority that is currently given to native species at the expense of a more flexible and functional approach should be reconsidered to avoid limiting options for adaptive conservation through the law.

\section{Valuing "wildness" and in situ conservation}

The prominence of the Tasmanian Wilderness World Heritage Area in the Tasmanian framework places explicit value on the importance of nature in an undisturbed state. This is also the case in the threatened species law: the first objective of the TSPA is to ensure that "native flora and fauna in Tasmania can survive, flourish and retain their potential for evolutionary development in the wild" (Sch 1, c13, emphasis added). "Wild" is defined as "an independent, unpossessed or natural state and not in an intentionally cultivated, domesticated or captive state regardless of the location or land tenure" (TSPA s3).

International, national, and state law all emphasize the importance of in situ conservation. However, with the rapidity of climate change, coupled with habitat fragmentation, likely to undermine the capacity of some species to independently evolve and/or adapt, human intervention in the form of restoring largescale ecological connectivity and/or assisted colonization is likely to become increasingly necessary (Braverman 2014). Terms such as "wild" and "natural" are therefore increasingly unhelpful in directing conservation outcomes under anthropogenic climate change (Pritchard and Harrop 2010). This is not to say that protecting areas of "wilderness" is not valuable. Rather, it may become necessary to adjust our understanding of "the wild" by accepting a higher level of human influence in the form of active conservation management, in order for some species to persist in those places. In this regard, Meine's (2015: 91) "relative wild: the degrees of wildness and human influence in any place, and the ever-changing nature of the relationship between them over time" may provide a useful terminology.

\section{Focus on sites}

Conservation law has developed with an emphasis on the reservation of parcels of public land for conservation purposes. Even if private reserves are included, the emphasis on reserves with well-defined spatial boundaries implies that natural resources outside those boundaries remain available for exploitation (Preston 2013, McCormack and McDonald 2014, Fitzsimons 2015). This implies that conservation should primarily take place within defined areas and reinforces a distinction between "wild" protected places and places that are "tamed" for human use. This distinction may undermine the potential for integrated, landscape-scale conservation planning across tenures that recognizes the importance of connectivity, refugia, and healthy landscapes surrounding protected areas (Laurance et al. 2012).

\section{A SYSTEMS APPROACH TO CONSERVATION OBJECTIVES IN LAW}

Much of the climate adaptive conservation literature advocates a shift toward systems and landscape approaches to conservation, rather than protection of specific species. Recognizing the social and cultural importance of retaining populations of iconic species in the wild, we do not advocate a wholesale replacement of species-level conservation. Even if we did, the difficulties of system-wide approaches should not be understated. The barriers to implementing new objectives are considered below, but a key reason that current approaches perform poorly is because they have been inadequately funded, and there is little evidence to suggest that a new set of objectives would come with enhanced resources for implementation. Furthermore, legal structures are rarely the product of intentional institutional design, instead representing the product of trade-offs among competing interests. Rather than proposing a wholesale replacement of current approaches, therefore, we point to three key changes to current objectives that would facilitate a transition to more climateadaptive conservation legal frameworks. They are:

1. acknowledgment in conservation law of system dynamism;

2. focus on function, stability, and resilience, as well as level of threat; and

3. an explicit recognition that systems operate at multiple scales, and therefore, require multiscalar management.

Social-ecological systems are both spatially and temporally dynamic. Conservation objectives must, therefore, make express allowance for the certainty of change over time. Explicit recognition of change processes could translate into some areas becoming more or less important in conservation terms. As noted by a workshop participant:

Maybe an area that is a reserve stops being a reserve
because everything dies back, and it might work the other
way because areas that are currently less protected may
need to become more protected as refugia because they
then become suitable. It is that change over time and
ensuring that the provisions of how we divide and
designate land use allows for that change.

Given the diverse values of protected areas, we do not advocate that reserves should be degazetted if they no longer protect threatened species. It will be important to ensure that adaptive management approaches are used to promote more conservationfocused objectives, and not to justify dilution or compromise of protected area values. Rather, protected areas should be designed and managed in ways that facilitate adaptation to change. Diverse habitats in good condition currently in reserves are most likely to be resilient to change in the short term and have greater adaptive capacity in the long term. More dynamic and flexible practices could be promoted by requiring, through appropriate legislative mandates, that protected areas be managed for adaptation to climate change (Scott and Lemieux 2005).

The legal definition of habitat also needs to change. As noted previously, in Tasmania, it relates only to the area currently occupied by a listed species. The glossary to the Australian Capital Territory's recent Nature Conservation Act 2014 (NCA ACT), on the other hand, defines "habitat" as an area that is or "was once 
occupied (continuously, periodically or occasionally) by an organism or group and into which organisms of that kind have the potential to be reintroduced." This definition recognizses that changes to species distributions may leave ecological niches unfilled. Whether the NCA ACT definition will result in practical changes to conservation practice remains to be seen, but the new Act does afford greater flexibility in the areas deserving of conservation management.

Having a stronger focus on drivers of change may also involve a shift in focus from in situ conservation to ensuring continued existence of species, with the specific locations and abundances of species seen as transient (Dunlop et al. 2013). This would then pave the way for wider use of assisted colonization, translocation of species and the establishment of "insurance populations" in areas that are more climatically favorable. New legal tools may be required to facilitate such measures. A shift toward ex situ or translocated conservation would also involve a change to the objectives of protected area management. Although some areas may remain subject to restoration-oriented interventions that are aimed at maintaining the area at some historical baseline, most will either be allowed to adapt naturally to changing conditions or have innovative or experimental interventions aimed at accommodating new species and ecological assemblages.

Adaptive conservation objectives may need to focus more on system functions:

\section{At the moment, we have an obsession with compositional [biodiversity] - what's there, but we also need to take into account the structural-how it's arranged, and the functional - what it does. (Workshop participant.)}

This may mean conservation effort is directed toward non-native or neonative species that perform important functions in the landscape. Emphasis on systems over species may also demand reconsideration of the way that rarity is prioritized in Australian conservation law, with a possible shift toward a triage-approach to in situ conservation efforts (Weins and Hobbs 2015). However, there may be powerful social, cultural, and recreational reasons for ongoing conservation of iconic species, so the difference may initially be one of emphasis rather than object.

A systems approach also involves a shift in focus to planning at multiple scales, for the benefit of both species and ecosystems and ecological processes (Heller and Zavaleta 2009, Mawdsley et al. 2009, Polak et al. 2015). Although multiscalar management has been advocated for some time, it has enjoyed limited uptake. As noted by a workshop participant:

The Hawke review [of the EPBC Act] in 2009 recommended that the scale at which we consider and manage biodiversity be raised ... to look at landscapes and whole ecosystems and I think that has yet to happen.

A multiscaled approach that seeks to maintain ecosystem health under changing conditions could see bioregional scale objectives aimed at protecting ecosystems and species-level objectives that do not focus on maintaining current distributions (Dunlop et al. 2013). Explicit adoption of multiscalar approaches can provide a stronger rationale for concentrating on connectivity, including altitudinal and latitudinal connectivity along the land-coastocean continuum, and between public protected areas and private land. Recognition of unique qualities at local scales will also enable some areas to be managed in isolation in order to contain or keep out threats such as fire, invasive species, and disease (Prober and Dunlop 2011). A nested and integrated set of objectives across multiple scales could also help address problems of regulatory fragmentation and duplication that arise from Australia's federal model of environmental governance and enable regulatory efforts to focus on the scale at which relevant stressors and human activities occur.

\section{PATHWAYS TO REFORM}

The characteristics of law that ensure its stability, predictability, and consistency over time also make it slow to change. Enduring reform also requires strong community consensus. It is both likely and in some ways desirable that the conversation about reforming conservation objectives will take some time. From the considerations discussed in the previous sections, we have identified requirements for formulating legal objectives for biodiversity conservation and how the barriers to implementing such reforms might be addressed.

\section{Formulating objectives}

Even if the need for reform of conservation objectives is accepted, their ideal form is not settled (Hagerman et al. 2010). Similarly, it is not clear whether it would be better to prescribe changes to current conservation goals through existing legal instruments, or whether attention should focus on reforming the decision-making processes for conservation. Principle-based regulation defines the broad goals to be pursued and allows managers the freedom to achieve those goals and determine priorities for action and investment in the most efficient way (Bottrill et al. 2008). Parks Victoria took such an approach in developing the most recent protected area management plans for Victoria's Alpine (Parks Victoria 2014) and South West (Parks Victoria 2015) regions. These plans set broad conservation and management goals at the regional or landscape level, across tenures, ecological systems, and habitats, allowing site-specific management to be determined at the level of individual land parcels. Site-based management plans can thus be updated more regularly because the areas covered are smaller; the plans do not need to accommodate long timeframes and associated uncertainty (including in funding and climate and other ecological impacts); and the site-based plans will not require the same formal review periods that apply to traditional statutory management plans. More regular management planning reviews have the advantage of allowing climatic and ecosystem changes to trigger changes to the formal, agency, and private planning documents, allowing more adaptive approaches to management.

Process goals may provide an alternative framework for prioritizing and formulating intervention under climate change (Heller and Hobbs 2014) as they avoid prescriptions about how nature should be. Yet they lack the measurability required by contemporary adaptive management and accountability standards. The Parks Victoria plans noted above suffer from a similar limitation.

Where objectives are specified, the statutory duty should be to exercise powers and functions to achieve the conservation of biological diversity and ecological integrity and not merely to consider the matter in the exercise of a power or function (Preston 2013). This would overcome a key weakness of current 
approaches that simply require a balancing of competing interests. Balancing mandates typically privilege development, as decision makers lack clear guidance about how to exercise their discretion in such cases. As one workshop participant from the State Government noted:

\section{[I]n terms of the reality of how government approaches these things, actually identifying priorities-species and values for conservation - becomes a really important part. You can't do it all so we actually need our legislation to give some sort of guidance on what the priority areas are... "having regard to" versus "promoting," those words mean a lot when it comes down to making decisions.}

The form that new objectives should take must be part of a wider socio-political project and in thinking about embarking on such a project, it is necessary to consider its practical feasibility. To that end, the next section examines key barriers to reform, including potential adverse side effects, and the factors that might facilitate or enable reform.

\section{Addressing barriers to reform}

Barriers to conservation law reform derive from the way that environmental law generally is structured in the Australian federation, as well as popular views about what our laws should try to achieve (Australian Panel of Experts on Environmental Law (APEEL) 2015). To the extent that Australian law seeks to implement the requirements of the CBD, the emphasis of that convention on in situ conservation may be considered a barrier to reform, particularly given that the instruments of international law are notoriously hard to amend. Nonetheless, the 2014 Conference of the Parties to the CBD highlighted the key role of the Strategic Plan for Biodiversity 2011-2020 for promoting effective implementation of the Convention through a strategic approach, comprising a shared vision, a mission, and strategic goals and the Aichi Biodiversity Targets (CBD 2014). These targets (CBD 2010), although retaining an aspiration to prevent the extinction of known threatened species (Target 12), also promote the importance of well-connected systems of area-based conservation measures that are integrated into the wider landscapes and seascapes (Target 11) and enhance ecosystem resilience (Target 15). There are elements here of systems thinking that provide a basis for more adaptive specification of CBD aspirations. In any event, Australia's CBD obligations are formally met by the provisions of the EPBC Act. There is very minimal national oversight of the way in which state-based regimes operate, provided they do not undermine or contradict the national approach. Perhaps more problematic, therefore, is the sheer complexity of the conservation framework as it operates at the local level. There, management and development decisions are influenced by local land-use planning provisions and applicable resource development laws, as well as state and Commonwealth conservation requirements relating to specific listed species and ecosystems. Although the mandate of the CBD itself may not operate as a major barrier, therefore, the structural complexity of conservation governance-both horizontally across land-use sectors and vertically across scales of government -may well impede the effectiveness of any change to objectives in state-based conservation laws alone.

The complexity of existing regimes and the cost and resources required to develop the science needed to achieve conservation outcomes under climate change may also drive some reluctance to interfere with current approaches:

Even managing biodiversity as a static thing is really,
really challenging, so bringing in climate change
adaptation blows it out of the water again. I don't think
we've got a good handle on even resilient species and
communities, let alone broader concepts and realities.
(Workshop participant.)

The most persistent barrier identified by workshop participants was the lack of political will to consider biodiversity conservation generally, or climate-adaptive requirements in particular:

The other thing that is really striking in my work is how much biodiversity is actually perceived to be a dirty word out there.

There was a general view that the public lacked understanding of the future needs of conservation and commitment to reforming current approaches. A strong need was expressed for ways to begin this conversation at a wider community level. Others lamented what they perceived to be a general disinterest in evidence-based decision making in government, and a short-term and electorally popular prioritization of management activities on protecting assets and public safety.

A related issue concerns the fear that developing more achievable and adaptive objectives would simply dilute our commitment to strong conservation outcomes, rather than legitimately attempting to enhance them. Workshop participants did not explicitly identify this as a major barrier, yet it quickly arose as a major issue in subsequent informal discussions among the project team and with staff from environmental NGOs. This may be explained by the way in which options were presented and discussed in the workshop, which did not demand that participants make choices between threatened species approaches and a system-level approach that would tolerate explicit triage.

If a principles-based approach were to be adopted, some of the concern about lowering conservation standards might be allayed by formally adopting the nascent environmental law principle of "nonregression." Widely recognized in human rights law, nonregression in environmental law reform would mean that existing environment norms could only be revised if the change did not reduce standards of protection (Prieur 2012). It could be argued that embracing a more dynamic and systems-based approach to conservation objectives would not see regression in levels of protection, but would actually enhance conservation outcomes because it ensures that conservation efforts are informed by modern understandings of system dynamism and the multiple scales at which change occurs. Applying the nonregression principle to conservation objectives would mean that conserving individual species would remain a priority but that, in some cases, this would involve greater emphasis on ex situ efforts and on management that would benefit multiple species to promote overall system health. Indeed, it might actually result in a more enduring and meaningful approach to species conservation in the longer term.

A related concern among workshop participants was that merely updating objectives is pointless without addressing failures of implementation through specific legal tools: 
At the end of the day they [objectives] have to be achievable, it's a nonsense to set goals that aren't achievable.

It's good to have some aspirational objectives I guess, but the reality of actually getting them into a work plan for a ranger is a long way off.

Objectives at the high level need to flow through in the land-use planning regulations and be quite explicit in statutory instruments ... and at the moment there's not even clarity in whether species and communities have a place there, so if other concepts around adaptation of biodiversity have relevance, then that needs to be explicit.

Participants saw significant cobenefits in engaging in a wider public conversation about future conservation goals, especially in terms of achieving better alignment of goals in different regimes, addressing nonclimatic stressors, and reducing the economic inefficiencies of multiple legal requirements.

These factors are by no means unique to reforming conservation objectives or conservation law more generally, but they highlight the importance of taking a longer-term view of the overall reform project, and the need for a range of public information and engagement activities. In this regard, it will be essential to use respected and influential "champions" to lead this debate. In a state such as Tasmania, property owners who are engaged in both stewardship activities and economically productive land uses can offer insights into the potential for multiple benefits. Deeper engagement with Indigenous people was also seen as a key enabler of the debate needed to precede future reform.

The fact that Tasmania already has a good reserve system was also considered advantageous because it provides a significant land area over which to accommodate change and range shifts and allows for greater experimentation with multiscale management approaches.

\section{CONCLUSIONS}

The architecture of conservation laws is currently preoccupied with processes of species listing and development of recovery plans, front-end decision making, and environmental impact assessment procedures, and the establishment of protected areas. Current conservation objectives that seek to have it all in terms of in situ conservation of species and retention of protected areas as undisturbed, natural, or wild are likely to fail under future climate change. Even if they were fully funded, the aspiration to hold things to some historical baseline ignores the reality of current and future climatic shifts. Legal regimes need to be made more agile and responsive to changing ecological needs. In arguing for a shift toward a more dynamic, multiscalar approach to conservation objectives, we acknowledge the inevitability of changes to protected area management plans, greater emphasis on ex situ approaches, and the need for far deeper engagement with private landholders.

Changing conservation objectives alone will not effect these shifts. Reforming objectives is only the first step toward more fundamental changes to the legal tools and instruments that are used to achieve objectives. Indeed, whatever changes are made to objectives in legal regimes whose substantive focus is conservation, parallel reforms are needed in the resource management frameworks with impacts on biodiversity, such as mining, forestry, water, and land management.
Wholesale reform is unlikely to occur rapidly, and we have identified key barriers to reform of both objectives and the conservation regime itself. The ideal form for more adaptive conservation objectives is not settled. Options include the inclusion of principles or broad goals, like those outlined above, or the stipulation of more measurable prescriptions, or revision to processes by which priorities and funding are determined. A pluralistic approach to reform may be the most appropriate strategy, involving overarching, nonspecific conservation goals that operate across landscapes, sectors, and tenures, with more specific, measurable objectives that articulate priorities for action and investment.

Responses to this article can be read online at: http://www.ecologyandsociety.org/issues/responses. $\mathrm{php} / 8460$

\section{Acknowledgments:}

The authors gratefully acknowledge the participation of conservation stakeholders in this study.

\section{LITERATURE CITED}

Australian Panel of Experts on Environmental Law (APEEL). 2015. The next generation of Australia's environmental laws: introductory paper. APEEL, Sydney, New South Wales, Australia. [online] URL: http://apeel.org.au/\#/introductory-paper/.

Bell, P. J. 1998. Ptunarra Brown Butterfly Recovery Plan 1998-2003. Department of Primary Industries, Water and Environment, Hobart, Tas, Australia.

Bellard, C., C. Bertelsmeier, P. Leadley, W. Thuiller, and F. Courchamp. 2012. Impacts of climate change on the future of biodiversity. Ecology Letters 15:365-377. http://dx.doi. org/10.1111/j.1461-0248.2011.01736.x

Bottrill, M. C., N. L. Joseph, J. Carwardine, M. Bode, C. Cook, E. T. Game, H. Grantham, S. Kark, S. Linke, E. McDonaldMadden, R. L. Pressey, S. Walker, K. A. Wilson, and H. P. Possingham. 2008. Is conservation triage just smart decision making? Trends in Ecology \& Evolution 23(12):649-654.

Braverman, I. 2014. Conservation without nature: the trouble with in situ versus ex situ conservation. Geoforum 51:47-57. http:// dx.doi.org/10.1016/j.geoforum.2013.09.018

Camacho, A. E. 2010. Reassessing conservation goals in a changing climate. Issues in Science and Technology Summer: 2127.

Chaffin, B. C., H. Gosnell, and B. A. Cosens. 2014. A decade of adaptive governance scholarship: synthesis and future directions. Ecology and Society 19(3):56. http://dx.doi.org/10.5751/ ES-06824-190356

Convention on Biological Diversity (CBD). 2010. Aichi Biodiversity Targets. [online] URL: https://www.cbd.int/sp/ targets/

Convention on Biological Diversity (CBD). 2014. COP 12 Decisions, [online] URL: https://www.cbd.int/decisions/cop/?m= cop-12 
Craig, R. K. 2010. "Stationarity is dead"-long live transformation: five principles for climate adaptation law. Harvard Environmental Law Review 34:9.

Department of Primary Industries, Water and Environment (DPIPWE). 2013. Natural heritage strategy 2013-2030. Department of Primary Industries, Water and Environment, Hobart, Tasmania, Australia.

Dunlop, M., H. Parris, P. Ryan, and F. Kroon. 2013. Climateready conservation objectives: a scoping study, final report. National Climate Change Adaptation Research Facility, Gold Coast, Queensland, Australia.

Fitzsimons, J. A. 2015. Private protected areas in Australia: current status and future directions. Nature Conservation 10:123. http://dx.doi.org/10.3897/natureconservation.10.8739

Garnett S., and K. Zander. 2014. Finding new nests for birds threatened by climate change. The Conversation: 11 August 2014. [online] URL: https://theconversation.com/finding-new-nestsfor-birds-threatened-by-climate-change-28720

Gillson, L., T. P. Dawson, S. Jack, and M. A. McGeoch. 2013. Accommodating climate change contingencies in conservation strategy. Trends in Ecology \& Evolution 28(3):135-142. http://dx. doi.org/10.1016/j.tree.2012.10.008

Hagerman, S., H. Dowlatabadi, T. Satterfield, and T. McDaniels. 2010. Expert views on biodiversity conservation in an era of climate change. Global Environmental Change 20(1):192-207. http://dx.doi.org/10.1016/j.gloenvcha.2009.10.005

Hagerman, S. M., and T. Satterfield. 2014. Agreed but not preferred: expert views on taboo options for biodiversity conservation, given climate change. Ecological Applications 24 (3):548-559. http://dx.doi.org/10.1890/13-0400.1

Harris, R. M. B., O. Carter, L. Gilfedder, L. L. Porfirio, G. Lee, and N. Bindoff. 2015. Noah's ark conservation will not preserve threatened ecological communities under climate change. PLoS One 10(4): e0124014. http://dx.doi.org/10.1371/journal.pone.0124014

Harris, R. M., L. L. Porfirio, S. Hugh, G. Lee, N. L. Bindoff, B. Mackey, and N. J. Beeton. 2013. To be or not to be? Variable selection can change the projected fate of a threatened species under future climate. Ecological Management and Restoration 14:230-234.

Heller, N. E., and R. J. Hobbs. 2014. Development of a natural practice to adapt conservation goals to global change. Conservation Biology 28(3):696-704. http://dx.doi.org/10.1111/ cobi.12269

Heller, N. E., and E. S. Zavaleta. 2009. Biodiversity management in the face of climate change: a review of 22 years of recommendations. Biological Conservation 142(1):14-32.

Hoegh-Guldberg, O., and J. F. Bruno. 2010. The impact of climate change on the world's marine ecosystems. Science 328 (5985):1523-1528. http://dx.doi.org/10.1126/science.1189930

Hutchinson, T., and N. Duncan. 2012. Defining and describing what we do: doctrinal legal research. Deakin Law Review 17:83119. http://dx.doi.org/10.21153/dlr2012vol17no1art70
Intergovernmental Panel on Climate Change (IPCC). 2014. Climate change 2014: impacts, adaptation, and vulnerability. Part $B$ : regional aspects. Contribution of Working Group II to the Fifth Assessment Report of the Intergovernmental Panel on Climate Change Cambridge University Press, Cambridge, UK; New York, New York, USA.

Koontz, T. M., D. Gupta, P. Mudliar, and P. Ranjan. 2015. Adaptive institutions in social-ecological systems governance: a synthesis framework. Environmental Science \& Policy 5(B):139151. http://dx.doi.org/10.1016/j.envsci.2015.01.003

Laurance, W. F., D. C. Useche, J. Rendeiro, M. Kalka, C. J. A. Bradshaw, S. P. Sloan, S. G. Laurance, M. Campbell, K. Abernethy, P. Alvarez, V. Arroyo-Rodriguez, P. Ashton, J. BenitezMalvido, A. Blom, K. S. Bobo, C. H. Cannon, M. Cao, R. Carroll, C. Chapman, R. Coates, M. Cords, F. Danielsen, B. de Dijn, E. Dinerstein, M. A. Donnelly et al. 2012. Averting biodiversity collapse in tropical forest protected areas. Nature 489(7415): 290-294. http://dx.doi.org/10.1038/nature11318

Mawdsley, J. R., R. O’Malley, and D. S. Ojima 2009. A review of climate-change adaptation strategies for wildlife management and biodiversity conservation. Conservation Biology 23(5):10801089. http://dx.doi.org/10.1111/j.1523-1739.2009.01264.x

McCormack, P., and J. McDonald. 2014. Adaptation strategies for biodiversity conservation: has Australian law got what it takes? Environmental and Planning Law Journal 31:114-136.

McDonald, J. 2011. The role of law in climate change adaptation. Wiley Interdisciplinary Reviews: Climate Change 2(2):283-295.

Meine, C. 2015. A letter to the editors: in defense of the relative wild. Pages 84-95 in B. A. Minteer and S. J. Pyne, editors. After preservation. University of Chicago Press, Chicago, Illinois, USA.

Parks Victoria. 2014. Greater Alpine National Parks draft management plan. Parks Victoria, Melbourne, Victoria, Australia. [online] URL: http://parkweb.vic.gov.au/ data/assets/

pdf file/0012/629688/Alpine-Draft-Management-Plan-June-2014. pdf.

Parks Victoria. 2015. Ngootyoong Gunditj Ngootyoong Mara South West management plan. Parks Victoria, Melbourne, Victoria, Australia. [online] URL: http://parkweb.vic.gov.au/ data/assets/pdf file/0003/662763/NGNM-South-West-ManagementPlan.pdf.

Polak T., J. E. M. Watson, R. A. Fuller, L. N. Joseph, T. G. Martin, H. P. Possingham, O. Venter, and J. Carwardine. 2015. Efficient expansion of global protected areas requires simultaneous planning for species and ecosystems. Royal Society Open Science 2:150107. http://dx.doi.org/10.1098/rsos. 150107

Preston, B. J. 2013. Adapting to the impacts of climate change: the limits and opportunities of law in conserving biodiversity. Environmental and Planning Law Journal 30:375-389.

Prieur, M. 2012. Non-regression in environmental law. Surveys and Perspectives Integrating Environment and Society 5:2.

Pritchard, D. J., and S. R. Harrop. 2010. A re-evaluation of the role of ex situ conservation in the face of climate change. Botanic 
Gardens Conservation International 7(1):1-4. [online] URL: https://www.bgci.org/resources/article/0632/

Prober, S. M., and M. Dunlop. 2011. Climate change: a cause for new biodiversity conservation objectives but let's not throw the baby out with the bathwater. Ecological Management \& Restoration 12(1):2-3. http://dx.doi.org/10.1111/j.1442-8903.2011.00563. $\underline{\mathrm{X}}$

Rickards, L., J. Wiseman, T. Edwards and C. Biggs. 2014. The problem of fit: scenario planning and climate change adaptation in the public sector. Environment and Planning C 32(4):641-662. http://dx.doi.org/10.1068/c12106

Scott, D., and C. Lemieux. 2005. Climate change and protected area policy and planning in Canada. The Forestry Chronicle 81 (5):696-703. http://dx.doi.org/10.5558/tfc81696-5

Seabrook L., C. A. McAlpine, and M. E. Bowen. 2011. Restore, repair or reinvent: options for sustainable landscapes in a changing climate. Landscape and Urban Planning 100:407-410. http://dx.doi.org/10.1016/j.landurbplan.2011.02.015

Steffen, W., A. A. Burbidge, L. Hughes, R. Kitching, D. Lindenmayer, W. Musgrave, M. Stafford Smith, and P. A. Werner. 2009. Australia's biodiversity and climate change: a strategic assessment of the vulnerability of Australia\&\#8217s biodiversity to climate change. Australian Government, Canberra, Australian Capital Territory, Australia.

Wiens, J. A., and R. J. Hobbs. 2015. Integrating conservation and restoration in a changing world. BioScience 65(3):302-312. http:// dx.doi.org/10.1093/biosci/biu235 